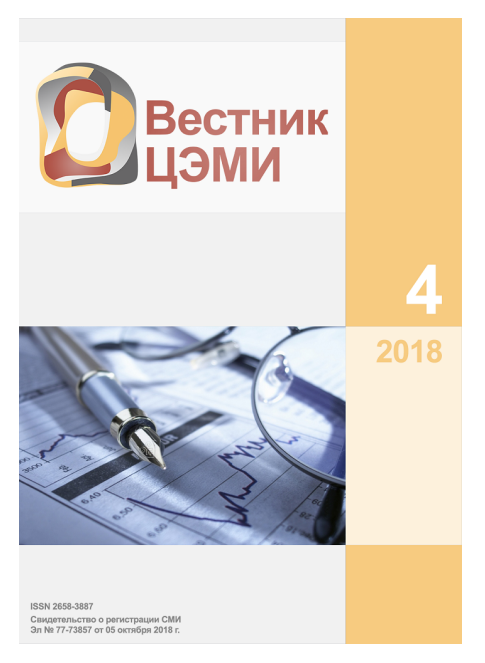

Вестник ЦЭМИ РАН. 2018-2023

ISSN 2658--3887

URL - $\underline{\text { http: } / / \text { cemi.jes.su }}$

Все права защищены

Выпуск 4 Том 1. 2018

\title{
Assessment of fair values and depreciation in buildings: new applications for the Discounted Cash Flow analysis
}

\author{
Смоляк Сергей Абрамович \\ Центральный экономико-математический институт РАН \\ 107564 Москва, Краснобогатырская улиия, 27 кв. 129
}

\begin{abstract}
Аннотация
The findings from this chapter are applicable to such Real Property accounting situations in which the value of land is assumed to be known, but the value of building erected on it (and, by implication, the value of overall property) needs be determined on the basis of known income arising from the overall property. As is well known, across most accounting regimes globally building is usually a depreciable element in the costbased accounting model, while a fee-simple land element in the property is deemed perpetual and not subject to depreciation-necessitating a separate accounting treatment for both elements in the overall property. Given this context, this chapter provides analytical framework and guidance to help accountants to do the following: 1) To determine the value of the building element for the initial recognition in the accounts of entities, without recourse to a meticulous buttom-up cost analysis (or unit costs) of substitution. 2) To justify the economically rational residual service life of the building element. 3) To establish the economically rational depreciation pattern for the building element. To achieve these objectives, this chapter uses a mathematical model formulated in continuous time and based on the well-known DCF analysis discounting principles, however, because the model is framed in continuous time its advantage is in that it allows for less burdensome forecast inputs (i.e. prospective financial information) than the conventional DCF format in discrete time. It uses the explicit assumptions for the rates of change as inputs, instead.
\end{abstract}

Ключевые слова: недвижимость, стоимость здания, оценка, амортизация, DCF анализ, математическая модель, оставшийся срок службы. 


\section{Ссылка для цитирования:}

Смоляк С. A. Assessment of fair values and depreciation in buildings: new applications for the Discounted Cash Flow analysis // Вестник ЦЭМИ РАН. - 2018. - Т. 1. Выпуск 4. URL: https://cemi.jes.su/s265838870000159-7-1/. DOI:

\subsection{6/S0000159-7-1}

\section{$1 \quad 1$. Income approach to the valuation of buildings as traditionally used}

2 Finding a fair value of a building is often performed through a process of income capitalization, i.e. by multiplying the annual income from the rental use of the building by a rent multiplier (RM). Multipliers can be developed from transactional data on similar buildings, usually for some period preceding the valuation date. However, in the process one must also adjust for the differences between the subject building being valued and its comparables. To introduce such an adjustment, it is important to know what factors affect the value of the RM and in which way. The associated analysis is usually based on the application of the Discounted Cash Flow (DCF) analysis to the valuation of property. The effectiveness of such an analysis is discussed in many research works, among which we shall only mention two noteworthy books [1-2] and two papers [3-4]. These three works also abound in references to earlier publications. Unfortunately, such an analysis is based on limited mathematical transformations involving the well-known cash-flow discounting formula, and a number of credibilitystretching structural constraints arising from an arbitrary projection period, over which a determinate change in income from the property (usually extrapolated by means of an arithmetic or a geometric progression) is assumed - along with the terminal (reversionary) value that the property will have at the end of the projection period. Below is illustrated a typical model of this kind.

3 The primary inputs into the model are: $B$-- annual net income from the use of the building (over the first year of the projection period), the income growth rate $i$, the duration of the projection period $T$, and a reversionary or residual value of the building at the end of the period -- $P$. It is assumed that income from the use of the building accrues at the end of each year, while the rate of income growth $(i)$ is less than the discount rate $(R)$. The value of the building at the valuation date $(C)$, at an annual nominal discount rate of $R$, can be determined by the DCF method as follows:

4

$$
C=\sum_{n=1}^{T} \frac{B(1+i)^{n-1}}{(1+R)^{n}}+\frac{P}{(1+R)^{T}}=\frac{B}{R-i} \times\left[1-\left(\frac{1+i}{1+R}\right)^{T}\right]+\frac{P}{(1+R)^{T}}
$$

5 It shall be noted that cash flow inputs to the model (including the net income) are on the pre-tax basis, therefore the discount rate $R$ is also nominal and pre-tax. The cash flows analyzed below are also deemed pre-tax.

Given this, what if a hypothetical situation arose where $i^{3} R$ ? In such a case, it would be appropriate to continue using the building indefinitely. Therefore, any real-life scenario must be such that the rate of growth in income from the use of the building is less than the discount rate. In situations where $T \circledR \sharp$, formula (1) is transformed into the well-known Gordon growth formula. 
7 To get a final value of the building, we have to make additional assumptions regarding its reversionary value. Usually one of the following assumptions is used:

8 1) Reversionary value is estimated as a proportion or certain fraction $(\gamma)$ of the "initial" value, i.e. $P=\gamma C$ (see [5]);

92 2) The value of the rent multiplier for year $T$-- $R M_{T}{ }^{--}$is known;

103 3) A ratio of rent multipliers at the beginning and termination of the projection period is known $k=R M_{T} / R M$.

11 For example, making assumption 1 transforms formula (1) into:

12

$$
R M=\frac{C}{B}=\frac{1}{R-i} \times\left[1-\left(\frac{1+i}{1+R}\right)^{T}\right] /\left[1-\frac{\gamma}{(1+R)^{T}}\right] .
$$

13 In the UK and U.S, assumptions like these, along with some others, enjoy a wide currency among property assessors (see [5-6]). Because similar formulas in countless different varieties are widely used, it is important to take note of a number of the significant attributes of these formulas.

14 1. They all recognize that the value of subject properties is affected by the income growth rates for these properties. This is a clear advantage of such valuation techniques. It is important, however, to bear in mind that there exist some requirements that have to be followed in establishing these rates. For example, the International Accounting standard IFRS 13 "Fair Value Measurements" urges caution in respect of the use of adjusted or unobservable inputs every time accounting Fair Value needs be ascertained, including under the income approach. Its paragraph B 15 also urges to account for risks even in case the cash flows are contractually determined. In a similar vein, appraisal standards dictate the need for consistency and moderation in inputs. For example, the International Valuation standard IVS 105 (2017 ed., see [7]). nowadays lists specific conditions in which the projections developed under the DCF/income approach should be accorded a "significant" weight and when the use of this approach could only be justified as a back-up option; additionally the standard lists the requirements for the use of "Prospective financial information (PFI)", including the rates forecasts, which should be market-adjusted in the context of market/fair value appraisals and consistent with the lifecycle of the asset being valued.

152 2. If the duration of the projection period, which constitutes a structural input into formula (1), is under 10 years, the last term in the formula will account for a significant contribution to the total value of property (up to $90 \%$ ). Therefore, to appraise a building with some accuracy, it will be necessary to estimate the reversionary value with the same accuracy. Thus, a resulting paradox: for us to be able to estimate the market value of a building today, we must be able to assess with exactly the same accuracy what its market value will be in, say, 10 years. The situation would not improve, were we to operate not with the reversionary value of the building, but rather with the ratio of the reversionary value to the "current" value, or to income as of the date of the reversion, -- since we would have to able to assess this relationship just as 
accurately ${ }^{1}$. Therefore, a fairly accurate assessment, downplaying the issues associated with reversionary values, is only possible if one chooses a sufficiently extended projection period. While this will not entirely do away with the issues involved in estimating the reversionary value, a less accurate assessment of the reversion become admissible on logical grounds.

16 3. The derivation of formula (1) is predicated on an assumption that the discount rate will remain unchanged during the projection period, while the income will grow at a constant rate (in other similar models, constant annual increments of income may be assumed). However, such an assumption would only hold in the context of a stable rate of inflation. Moreover, even if the rates of inflation and rates of growth for rental values have been steady and there are grounds to expect them to remain unchanged over the near-term, it may be unreasonable to project the same to hold over the next 10-20 years. It may seem easy to fix this flaw by introducing into the calculations a time-variable discount rate, as well as a rate of growth in rental values. However, the formulas would become much more complex, and the result would heavily depend on the forecasts made by the appraiser/accountant.

17 4. If the projection period is sufficiently long, then it becomes appropriate to consider the physical and functional deterioration of a subject building. It is not very clear how to incorporate this consideration into models of this type (similarly, the same criticism can be leveled against the Gordon formula and many of its modifications).

$18 \quad 5$. The derivation of formula (1) assumes that neither the length of a projection period, nor the reversionary value of the subject building depends on the characteristics of the underlying land. However, this assumption is not obvious and, as we shall see, may be inappropriate.

\section{2. Income from building use}

20 The "subject property" as a fixed asset in accounting usually comprises both the building being valued plus the land on which it is sited (so we shall talk about the "overall property"). It is assumed that the use of the property brings its owner a certain income (e.g., in the form of a rent), and such income accrues on account of the building itself, not the land. Thus, if the tenants are provided, for example, with car parking space, it is assumed that such services are included in the building rents. Our objective is to determine the value of the overall property subject to valuation, but in the process we shall assume the value of the underlying land to be known. So, essentially, the model we shall be developing is a building valuation model. To this end, we will propose models also based on the present value approach, but such as do not require long-term forecasting.

21 So far we keep mentioning the "income" associated with the use of a building, but have not discussed the concept. At the same time, while using the DCF method, we must consider not only the income (cash receipts, cash inflows) to the owner, but also the associated expenditures (cash outflows). Indeed, even when a space in the building is leased for rent, the landlord has to incur some expenses/outgoings that are not included in the rent. Typically, these costs are minor and they are either ignored or accounted for as a certain percentage of the rent, but it would appear that such costs must generally be considered as their value is significantly dependent on the condition of the building(s). 
At the same time, it should be noted that the value of property in our example is independent of whether it has been acquired in an equity settlement or with borrowed funds. So for the purpose of this article it shall be assumed that the purchase of the property is fully funded by the buyer's equity.

22 It should be noted as well that the notion of "income" is used in practice to describe a number of disparate economic indicators. Therefore, we will hereinafter opt to use the more neutral-sounding term, "benefits", often encountered in the International Valuation Standards (IVS) ([8]) Hereinafter we will deal with three value-defining income characteristics of the subject property.

23 1. Gross benefits - gross income to the property owner (from leasing the premises and servicing tenants).

24 2. Operating expenses. Usually pre-tax operating expenses do not include building depreciation charges and income taxes. The value of subject property we need to determine may have an impact on some costs - so-called ad valorem costs of the property owner. Such ad valorem costs include property taxes and insurance costs. On this basis, such ad valorem costs are excluded from operating expenses. Another exclusion has already been mentioned in connection with the mortgages to acquire the property: interest and repayments on mortgage loans are similarly disregarded in the calculations of operating benefits (instead, being allocated to the main activities of the building owner, rather than activities associated with the use of the building).

25 While the model developed is deterministic, it allows an accounting for some of the risk factors. Thus, if the use of a building involves the renting out of space, the landlord assumes the vacancy risk (in the interval between the departure of one tenant and the occupancy by another) as well as the risk of the loss of rent (when a tenant moves out without having settled with the landlord). These risks can be taken into account by reducing gross benefits by appropriate adjustment factors ${ }^{2}$.

$26 \quad 3$. Operating benefits (OBs) -- gross benefits less deductions for the operating expenses incurred by the owner. This measure can be justifiably considered to be on the pre-tax basis in the context, since it is being determined gross of ad valorem property taxes and would be better suited for collecting and analysing data related to the incomes and expenses of the property owners. In terms of its composition and scope, it is close to Earnings before interest, taxes and depreciation/amortization (EBITDA), but is not identical to it. Our definition, however, fully accords with appraisal practice, where "pretax" qualification only applies to cash flows and operating benefits before income tax, while cash flows and performance indicators prior to the payment of other taxes are generally of minor interest.

$27 \quad$ Also to be noted is that the value of a property assessed for the purposes of insurance and taxation may, in practice, differ from its market value, although both values should bear a close relationship to each other. In view of this, the model we develop should assume that ad valorem expenses per unit of time associated with the building are proportional by a certain fraction $m$ to the fair value of the building $C$, while ad valorem levies associated with the land stand at a certain fraction $q$ to the fair value of the land $L$. 
The building is used continuously, and it always requires operating expenses to be incurred. On this basis we model the process in continuous time. Accordingly, the rates of change in economic performance and the discount rates which we will be discussing below shall be continuous, rather then annual rates. So if we say that such and such a metric is growing at rate $z$, we mean that over a small increment of time, $d t$, it will have grown by $100 z d t \%$ or have sustained a $(1+z d t)$ times increase, while its growth over a year would then amount to $e^{z}$ times, and over $T$ years -- to $e^{z T}$ times. The relationship between the continuous $(z)$ and annual $(Z)$ growth rates (expressed as decimals and similarly "dimensioned", e.g. as reflecting a rate of change per annum) is represented by the following: $z=e^{z}-1, z=\ln (1+Z)$. Similarly, we will use a continuous discount rate $r$, which is linked to the annualized rate according to the well-known formulas: ${ }^{R=e^{r}-1,} \quad r=\ln (1+R)$. Thus, the income or expense incurred at time $t$, is discounted to its present value estimate at time 0 using a discounting factor of $e^{-r t}$, which at small values of $t$ is approximately equal to $1-r t$.

29 Since the process of benefit generation by the building is considered in continuous time, we will assume as its defining characteristic a rate ("intensity") of OBs generation, i.e. the size of OBs produced during an incremental unit of time. Therefore, if such a rate at a certain date (for example, the valuation date) is equal to $B$ (say, dimensioned in currency units per annum), then over an incremental interval of time, $d t$, the operating income accruing to the owner of the building will amount to $B d t$. Further, when discussing the rent multiplier, we will assume it is calculated as a ratio of the value of the property building element to the rate of operating benefits generated by the property as of the date in question.

30 Over time the OBs rate associated with the building sustains a change influenced by the following three factors:

31 1. Inflation. At times when prices for goods, labor and services in the country generally increase, the rents which reflect the value of the occupancy of a building over a unit of time (or the value of the right to use a building over a unit of time) also appreciate. The need to incorporate the rental rate growth into the property valuation process is well supported in a number of sources, e.g. reference source [4]. It is important not to lose sight of the fact the growth rate of prices for certain goods and services may vary for different sorts of goods and deviate from the rate of overall inflation, which reflects the average rate of price growth in the country. It follows, as well, that the growth rate in gross benefits will not in general be equal to the general inflation rate.

32 2. Physical deterioration. Buildings age over time. Therefore, the owner has to incur larger and larger expenses to provide for building maintenance and repairs. This subject is also explored in $[2,6]$. The overall result is that the owner's costs keep rising while his net benefits are reduced.

33

3. Functional obsolescence. Over the useful life of the subject property, other newer buildings commissioned by investors become available, supplying occupants with a wider range of services (amenities). Such buildings may be more attractive to some tenants who occupy space in the subject building or in similar properties. Faced with such a situation, the building owner is compelled to reduce his rental expectations 
somewhat and, hence, sacrifice a part of his income to ensure that the space in his building continues to be leased at full capacity.

34 The nature of the effects of these three factors on the owner's benefits varies substantially. Changes in market prices affect the building owner's income almost immediately. The effect of physical deterioration unfolds gradually, expressing itself in miniscule cost increments barely discernable over a short-term. Functional obsolescence is usually absent in un-outmoded buildings, becoming discernable only after the most recently designed buildings hit the market, offering their occupants up-to-date amenities. On balance, the resulting effect over the lifetime of the building may produce an average rate of change for OBs generated by the building that is less than the rate of general inflation, and that sometimes even shifts to negative territory.

\section{3. Land value as a factor defining the limit to the effective use of the buildings}

36 As already noted, a subject building forms an element of the overall property comprising both the building and the land on which it is situated (allowing for all the necessary environmental amenities, for example, green spaces and ground services on the building site). We shall assume the value of land as at the date of valuation, $L$, to be a known variable. In addition, it will be further assumed that the rate of change in the value of land $j$ is known as at the valuation date (it can be estimated by analyzing trends in the unit value of acreage for similar plots). In this section, we shall not consider taxes payable by the building owner.

37 Prior to the valuation date, the subject building could have been put to an arbitrary use, but its fair valuation, in line with IFRS 13 requirements (IFRS 13, p.31,), should be predicated upon the highest and best use that can be achieved in the future (IFRS 13; see also [6-7]). Knowing this use (which often coincides with the existing use), the assessor/accountant can estimate a rate $B$ at which the benefits (OB) are generated by the building.

38 The value of land generally increases over time. However, the respective growth rate $(j)$ cannot exceed the discount rate. Indeed, if it were otherwise, one might acquire land without caring to put it to any productive use and re-sell it after a certain holding period (at a higher price); one would have, thereby, generated a return at least commensurate with alternative highest and best investment opportunities. However, an opportunity for earning such superior returns on similar speculation is not borne out by customary business practice.

39 We assume that the subject property is one of the properties exchanged on the (real or virtual) market where properties similar to it are also available (properties which are generally characterized by different values for $L$ and $B$ ). Among the buildings offered on this market may be ones which have "no value". Their ongoing use, whatever it is, would be inefficient; however, they may be purchased for the sake of the underlying land. Let us explore how to "draw the line" separating the buildings "which are worth something" from those which are "of no value".

$40 \quad$ To do this, let us first note that even similar buildings situated on similar land may produce incomes of different magnitudes. One of the reasons for that may lie in the 
age difference of the buildings. Even given the same level of "amenities" (and, therefore, the same level of rent), older buildings typically entail higher maintenance and repair costs. Quite often older buildings are also less "comfortable" than the newer ones built to a modern design and providing their occupants with a wider range of facilities and amenities. In such instances, the rental rates and, hence, the owner's (lessor's) income from older buildings would happen to be less.

41 At what "critical value" of OBs does the value of the buildings go down to zero? It may seem that as long as a building generates at least some income, its value will remain positive, such that the "critical value" threshold will also equal zero. However, such a view is erroneous. The fact of the matter is that the magnitude of OBs generated by a building does not fully characterize the efficiency of its use over a given interval of time, because it fails to reflect the owner's capital gains or foregone income. The reason is that a part of the building owner's capital is also tied up in the underlying land, the value of which may increase over time. Thus, even though the building may produce zero or even negative benefits over some periods, the owner's capital may be augmented by the rising value of the land. From this it follows that the value of the land must somehow affect the most effective timing for termination of the building use (i.e., the time for selling the overall property at the price of the land). To identify how this effect is exerted, the following arguments are presented.

42 Consider an overall property comprising a building and the underlying land at a moment in time when selling it becomes the most effective strategy to pursue. Obviously, the value of the building would approach zero at this point, and the value of the overall property would equal the value of the land $L$.

43 Let us consider what would happen if the sale of the property were postponed for an incrementally brief period of time $d t$. For the purpose of simplicity, we shall assume that there are no ad valorem costs.

$44 \quad$ Use of the building over this $d t$ period would bring its owner net operating benefits $B d t$. Moreover, the value of the underlying land would have changed over the period. Let $j$ be the continuous rate of change in the value of the underlying land as of the valuation date (determinable through analysis of unit market price levels for comparable parcels of land). Then the value of land by the end of period $d t$ will have grown by $(1+j d t)$ and have reached the magnitude of $(1+j d t) L$, while the value of the building remains at zero. Consequently, the overall property could then be sold at the price of the land $(1+j d t) L$. In this case, the net discounted income from the use of the building over the period $d t$ and its subsequent resale will amount to $\frac{B d t+(1+j d t) L}{1+r d t}$, where $r$ is a continuous discount rate reflecting returns on alternative most effective investment opportunities. Having considered, per the stipulation, that the sale of property as of the valuation date, rather than after the lapse of period $d t$, is to be viewed as the most efficient strategy, the following condition obtains: $\frac{B d t+(1+j d t) L}{1+r d t} \leq L$, from which it follows that $^{B \leq(r-j) L}$. As has been demonstrated above, $r-j>0$. Thus, the value of a building remains positive as long as the rate of operating benefits from its use exceeds $(r-j) L$ and goes down to zero when this rate becomes level with $(r-j) L$ :

$45 \quad B=(r-j) L$. 

their location on land parcels of different values, one can see that the higher the land value, the shorter the economically justifiable lifetime of the building.

$47 \quad$ Let us therefore introduce an index of Payback Period for Land (PPL) - i.e. the ratio, $p=L / B$, which relates the value of the land to the rate of OBs generated by the building and shows a period during which the land investment would have been recovered through operating benefits from the building use, were such benefits to remain at a constant level. The foregoing consideration demonstrates that in a case when $P P L$ exceeds $1 /(r-j)$, the continuation of building use for its intended purpose may become economically inefficient, and its value goes down to zero. This implies that the value of a building, and, hence, the rent multiplier $R M=C / B$, are somehow dependent on PPL.

\section{4. The principle of stable dependencies}

49 The application of the income capitalization method to valuing buildings presupposes that the value of rent multipliers is nearly the same for all the buildings that belong to the same category (similar buildings) and remains reasonably stable over time. The technique described below is also based on similar assumptions. However, as can be seen from the above arguments, rent multipliers are expected to differ for buildings with different PPLs. Therefore, a more accurate assumption would be that they are somehow dependent on the value of PPLs, but this dependence itself is stable, i.e. time-invariant, at least over shorter intervals of time near the valuation date.

50 Appraisal practice commonly relies on a similar assumption regarding the stability of value dependency on its determinant factors. In fact, it is the stability of these functional relationships which permits the transactional data recorded at some points in time to be applied to establishing the value of properties at other, proximate, points in time. (see [9])

51 The premise of stability for the functional dependencies employed by appraisers/accountants is an extremely important one and can be elevated to the status of a valuation principle.

52 The stable dependencies principle. If in valuing a property, the appraiser/accountant relies on a functional dependence linking its value to some determinant factors, such dependence should be stable, i.e. valid not only as at the valuation date, but also in respect of points of time in proximity to that date.

53 The stability of a functional relationship relied upon by the appraiser/accountant should either be stated as a particular assumption, or validated by market data from different moments in time.

$54 \quad$ The subsequent models, proposed below, are essentially predicated on the stable dependencies principle.

\section{$55 \quad 5$. A model for the rent multiplier accounting for ad valorem costs}

56 It will be recalled that we are considering a market in which similar buildings, generating benefits of a different magnitude and situated on the land of varying value, are being exchanged. Now, we specify an incrementally brief span of time $d t$ (e.g., a 
month), commencing from the valuation date, and make the following assumptions for all the properties under consideration on the market during this period of time:

57 a) that the value of underlying land is growing at one and the same (known) rate $j$, lesser than the discount rate;

b) that the rate of OBs generated by the use of each building is growing at one and the same (known) rate $i$, which is less than the nominal pre-tax discount rate $r$, which we assume to be known;

c) that the value of each underlying land is growing at one and the same (known) rate $j$, greater than the rate of OBs $(i)$;

d) that their rent multiplier is dependent on the Payback Period for Land $(p)$, where the corresponding dependency is deemed smooth ${ }^{3}$ and stable. This means that a functional dependence of the form $R M=f(p)$ can be justifiably assumed to hold both as at the valuation date and for the dates in proximity thereto, although the exact specification for the $f$ function is so far unknown.

61 It turns out that these assumptions ${ }^{4}$ are sufficient for identifying the unknown function $f$ and valuing the subject building. A method which would be used for arriving at the solution is in many ways similar to the one we proposed in [10-11] for estimating Percent Good Factors when assessing depreciation in items of plant and equipment.

62 Thus, for all buildings on the market at the valuation date and near that date within a brief increment of time, $d t$, we presume that one and the same relationship holds between the building value $(C)$, on the one hand, and the rate of generated OBs $(B)$ and the value of the land $(L)$, on the other:

$63 \quad C=B f(p)=B f\left(\frac{L}{B}\right)$.

64 Let us assume that the use of any one of such buildings over the incremental interval of time $d t$ is economically justifiable. Let us specify what the new values for the economic attributes $C, B$ and $L$ will be at the end of this period - with these new values being denoted by the diacritical mark (tilda) placed over the respective letter ( $\sim$ ). These "future" values for the building and the land, $\tilde{C}$ and $\tilde{L}$, can be deduced from the following considerations. During the period $d t$ the rate of OBs generated by the building will have changed by $(1+i d t)$ times, while the value of the land will have changed by a factor of $(1+j d t)$, thus ${ }^{5}$

65

$$
\tilde{B}=(1+i d t) B, \quad \tilde{L}=(1+j d t) L, \quad \tilde{p}=\frac{\tilde{L}}{\tilde{B}}=\frac{1+j d t}{1+i d t} p=p+(j-i) p d t .
$$

66 Incidentally, this shows that the continuous growth rate for $P P L$ is equal to $j-i$, and, as observed at the conclusion to Section 3, this rate is positive.

67 The value of the building after the interval $d t$ has elapsed, in this case, (with the accuracy up to infinitesimals of a higher order) is:

68

$$
\tilde{C} \approx(1+i d t) B f(p+(j-i) p d t)=B f(p)+i B f(p) d t+B f^{\prime}(p)(j-i) p d t .
$$

69 On the other hand, the value of the property at the valuation date can be estimated using the discounted cash flow (DCF) method in its alternative form as stated 
below: The value of overall property at the valuation date is equal to the sum of operating benefits produced by the use of the property over an incrementally brief period of time $d t$ and the value of the property at the end of this period - discounted (at a pretax rate $r$ ) back to the valuation date.

70 If we value a property using this principle, the result can be regarded as a valuein-use, defined in a sense of the Impairment standard IAS $36^{6}$.

71

72

$$
B-m C-q L+i B f(p)+B f^{\prime}(p)(j-i) p+j L-r(C+L)=0 .
$$

In applying this DCF formulation, it should be noted that:

- the value of the overall property at the valuation date is equal to the sum of the values for the building element and the underlying land $(C+L)$;

- the value of the same property at the end of the period is equal to $\tilde{C}+\tilde{L}$;

- operational benefits $B d t$ arising from the use of the building over period $d t$ are infinitesimal and, with an accuracy up to higher-order infinitesimals, can be attributed as occurring at the valuation date;

- ad valorem costs per unit of time amount to $m C+q L$, where $m$ and $q$ - are the rates of expense per unit of time, proportional to the value of the building and land, respectively. Over the incrementally brief $d t$ period, the ad valorem costs would amount to $m C d t+q L d t$. They are also infinitesimal and can be attributed as occurring at the valuation date.

In this case, the presented DCF framework provides:

$C+L=B d t-m C d t-q L d t+(1-r d t)(\tilde{C}+\tilde{L})$.

Relying on formulas (3), (4), and (5), we can also deduce from this:

$$
\begin{gathered}
0=B d t-m C d t-q L d t+(1-r d t)(\tilde{C}+\tilde{L})-(C+L)= \\
=(B-m C-q L) d t+(\tilde{C}-C)+(\tilde{L}-L)-r(C+L) d t= \\
=(B-m C-q L) d t+i B f(p) d t+B f^{\prime}(p)(j-i) p d t+j L d t-r(C+L) d t .
\end{gathered}
$$

This equality is fulfilled if and only if:

Substituting $B f(p)$ for $C$ and $B p$ for $L$, and introducing simple transformations, this equation contracts to:

$83 \quad(j-i) p f^{\prime}(p)-(r+m-i) f(p)+1-(r+q-j) p=0$.

A solution to this equation will be presented for a typical case where $i$ 
$87 \quad$ And develop a resulting valuation equation. The resulting equation will hold true, however, only for those buildings whose intended use is economically feasible as at the valuation date.

88 In Section 3 we concluded that the PPL value for such buildings -- the ratio of the value of underlying land to the rate of OBs generated by the building -- should not exceed the threshold level of $1 /(r-j)$. It appears that, given $i$

$89 \quad$ Indeed, consider a building in our market, the intended use of which is not economically justifiable. Then the value of the corresponding property would be greater than the discounted sum of the benefits from its use arising over the dt period and the value of the property at the end of that period. In other words, the approximate equality (6) would transform itself (with an accuracy up to infinitesimals of a higher order) into an inequality:

90

$C+L \geq B d t-m C d t-q L d t+(1-r d t)(\tilde{C}+\tilde{L})$.

$91 \quad$ Note that the value of such a building as at the valuation date is zero, and it will remain at zero at the end of the period, such that $C=\tilde{C}=0$. In addition, $\tilde{L}=(1+j d t) L$, and, consequently, this inequality takes the following form:

92

$$
L \geq B d t-q L d t+(1-r d t)(1+j d t) L \approx L+B d t-L(r-j+q) d t .
$$

93 Obviously, this inequality would only hold when $L(r+q-j) \geq B$, i.e. when $p \geq 1 /(r+q-j)=s$. Hence $L \geq B$ s applies to the building under consideration. Therefore, a solution to (7) must become zero at $p=s$. By utilizing conventional methods for solving equation (7), given the condition $f(s)=0$, we obtain:

$94 \quad R M=f(p)=\frac{1}{r+m-i}\left\{1-\frac{\alpha}{\alpha-1}\left(\frac{p}{s}\right)+\frac{1}{\alpha-1}\left(\frac{p}{s}\right)^{\alpha}\right\}$.

95

$$
C=B f(p)=\frac{B}{r+m-i}\left\{1-\frac{\alpha}{\alpha-1}\left(\frac{L}{B S}\right)+\frac{1}{\alpha-1}\left(\frac{L}{B S}\right)^{\alpha}\right\} .
$$

96 We have thus deduced the desired formulas for the rent multiplier and the value of building element. The detailed examination of the rent multiplier formula shows that it differs from the Gordon formula (in continuous time) by the presence of a correction factor reflecting the impact of PPL. It shall be noticed that $i<j<r$, thus $\alpha>1$ and the dependence of RM on PPL will almost be linear at small values of PPLs.

$97 \quad$ Naturally, this formula is valid only when $p$ s. It is interesting to note that at $p=s$ not only does the value of the rent multiplier function go down to zero, but also that of its derivative with respect to $p$. This means that the graph line plotting the dependency of $R M$ on PPL becomes tangent to the $x$-axis at $p=s$.

$98 \quad$ These findings call for a few important comments. 

use, but also by the value of the underlying land and its respective growth rate.

2. Unlike in traditional DCF models assuming a constant growth rate for income arising from the building use, our model utilizes this assumption only in respect of an incrementally brief period of time in the neighborhood of the valuation date. Therefore, the application of the derived formulas doesn't require a long-term forecasting for the nominal discount rates and inflation rates, and doesn't presuppose the constancy of these rates over the useful life of the building. Therefore, these formulas are less "prospective financial information" intensive compared to the conventional DCF forecast framework.

3. As can be seen from formulas (9) and (10), the value of the buildings depends only on the differences $j-i, r-j$ and $r-i=(j-i)+(r-j)$. The first of these differences, as has been shown above, reflects the rate of growth for PPL; the second, the loss incurred from having invested capital tied up in land to be subsequently resold rather than in the best alternative investments available; and the third difference, representing the sum of the first two. Since the rate of general inflation (GDP deflator) in a country affects $r$, $i$ and $j$ in roughly the same way, the change in inflation rates should not greatly affect the value of the rent multiplier.

102 Here is an example (in this and following examples variables $r, i, j, m$ and $q$ are dimensioned as fractions of one per year (1/year)).

103 Example 1. The following table (Table 1) summarizes the results of valuation for four different properties under formula (10) at $r=0.08$ and given the presence or absence of ad valorem costs.

104 Table 1 Valuation of the building element $(C)$ at different value-affecting parameters for the building and their growth rates

$\begin{array}{lllllll}\text { № } & B \text { \$ths'd per year } & L \$ \text { ths'd }^{\prime} i \text { year }^{-1} & j \text { year }^{-1} & \text { C } \$ \text { ths'd } & \\ 1 & 60 & & & & m=q=0 & m=0.03, q=0.02 \\ 2 & 60 & 120 & 0 & 0.06 & 661 & 627 \\ 3 & 60 & 120 & -0.02 & 0.06 & 523 & 491 \\ 4 & 60 & 120 & 0 & 0.02 & 630 & 603 \\ & 240 & 0 & 0.06 & 588 & 517\end{array}$

$105 \quad$ Fig. 1 charts the $R M=f(p)$ dependency for various combinations of $j-i$ and $r-j$, given the absense of ad valorem costs $(m=q=0)$. How these dependencies change following the introduction of property taxes $(m=0.03, q=0.02)$ is shown in Fig. 2, which charts a case relating to $j-i=0.05$ situation.

106 It would appear from Fig. 2 and Table 1 above that a separate treatment of ad valorem costs brings about a reduction in the value of the buildings. However, such a conclusion is unjustifiable. The fact of the matter is that such treatment changes the composition of operating benefits, and increases their magnitude (exactly by the amount of ad valorem expenses); consequently, PPLs are reduced. Therefore, the valuation results obtainable with and without a separate accounting for ad valorem costs, given the same values for $\mathrm{OBs}$, are not directly comparable. 


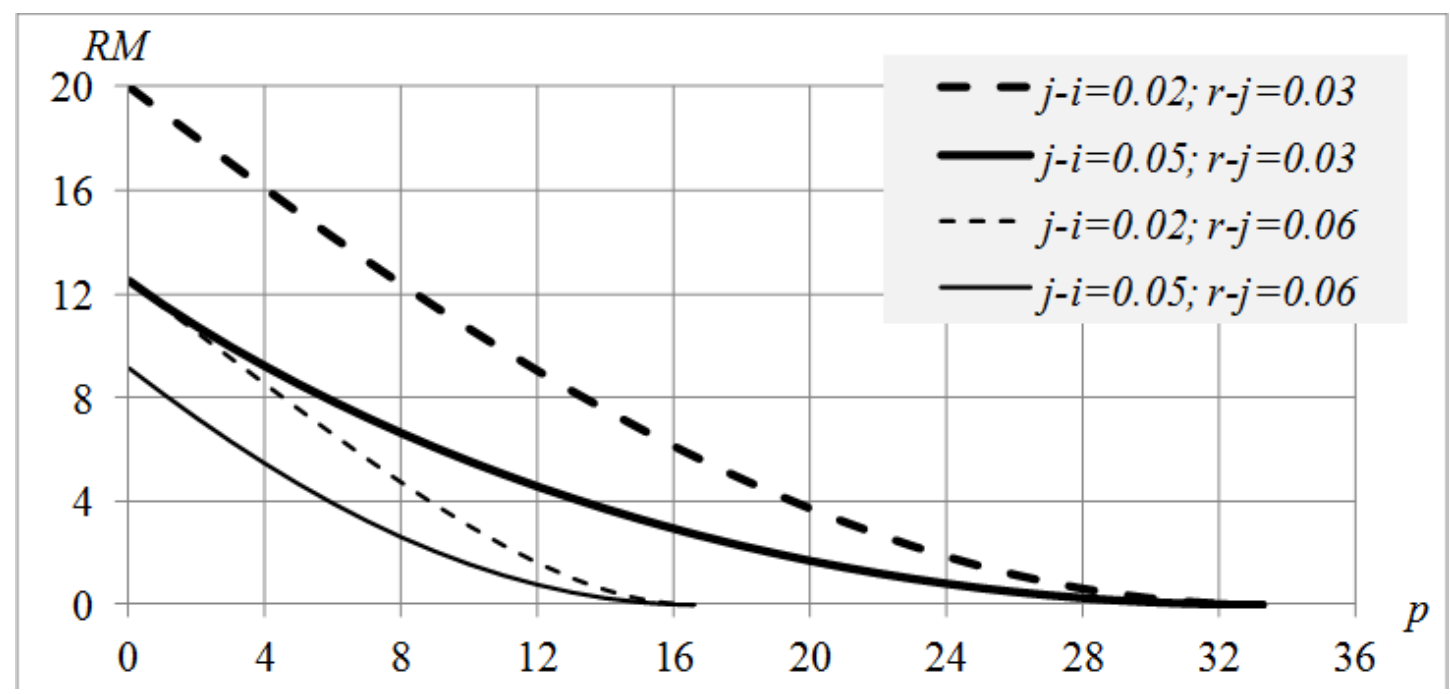

Fig. 1. The dependence of the rent multiplier on PPL for different values of $j$-i and $r-j$.

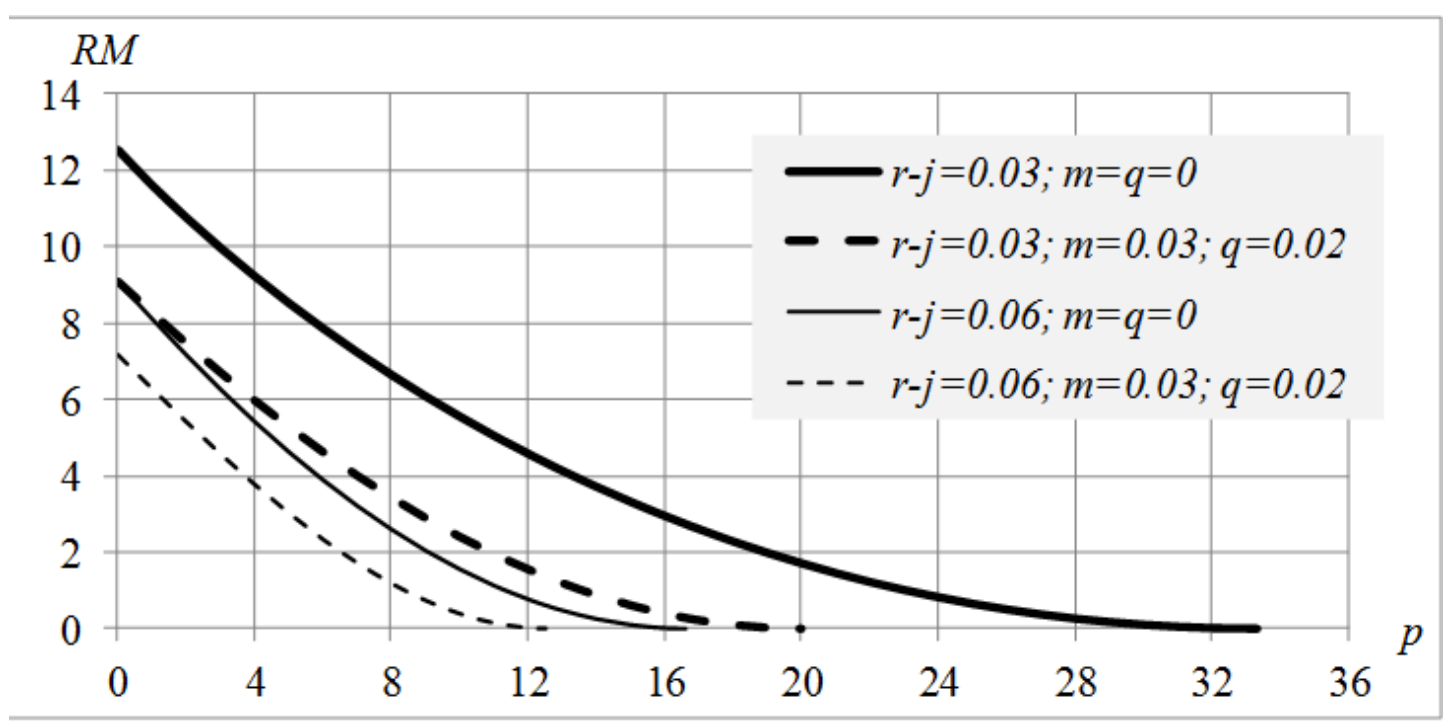

Fig. 2. The dependence of the rent multiplier on PPL for different values of $r-j, m, q$ at $j-i=0,05$.

\section{$109 \quad 6$. The use of market data for estimating the inputs to the model}

110 As shown by our estimates, a considerable impact on the value of the building element is exerted by the growth rates in operating benefits (i) and the value of underlying land (j). These rates can be assessed retrospectively on the basis of available statistics, but the respective estimates can also be cross-checked by market data as of the valuation date. A general idea of how to do it will be demonstrated below.

111 Suppose that the accountant has information on four or more comparables, i.e. properties similar to the subject one being valued. Specifically, for each comparable property $k$ the following is known: the value of the underlying land parcel $L_{k}$, the rate of benefits from the use of the building (in practical terms - the annual operating benefits) $B_{k}$ and the selling price of the building $C_{k}$. Having regard to these data, each comparable can then be characterized by a Payback Period value for the land $P_{k}=L_{k} / B_{k}$. If the proposed model specifications are valid, the actual values of 
comparables should be close to those estimated according to formula (10). This means that the following approximate equality should hold for each $k$ :

112

$$
C_{k} \approx \frac{B_{k}}{r+m-i}\left\{1-\frac{\alpha}{\alpha-1}\left(\frac{L_{k}}{B_{k} s}\right)+\frac{1}{\alpha-1}\left(\frac{L_{k}}{B_{k} s}\right)^{\alpha}\right\} .
$$

113 Keep in mind that the values for $s$ and a are associated with the parameter values $i$ and $j$ being sought according to equalities (8): ${ }^{s=\frac{1}{r+q-j} ;} ; \alpha=\frac{r-i+m}{j-i}$. Having assumed a specific value for the pre-tax discount rate $r$, what remains is to select a combination (i,j) such that the equalities (11) were to hold for each and every comparable as closely as possible. This can be achieved with "fit a parameter" functions of statistical software packages.

$114 \quad$ Below is an example to illustrate this. The annual nominal pre-tax discount rate of $12 \%=0.12$ is used. Assume $q=0.01$, and $m=0.032$. The data on seven comparable properties are given in the columns of the following table 2.

115 Table 2

$\begin{array}{llllllll}\text { Property } & 1 & 2 & 3 & 4 & 5 & 6 & 7 \\ B & 60 & 36 & 40 & 50 & 60 & 32 & 80 \\ L & 90 & 110 & 140 & 100 & 150 & 175 & 100 \\ C & 450 & 220 & 250 & 350 & 400 & 145 & 625 \\ p & 1.50 & 3.06 & 3.50 & 2.00 & 2.50 & 5.47 & 1.25 \\ R M & 7.50 & 6.11 & 6.25 & 7.00 & 6.67 & 4.53 & 7.81 \\ R M_{C} & 6.970 & 5.790 & 5.456 & 6.589 & 6.210 & 5.790 & 7.160 \\ C_{C} & 452 & 228 & 240 & 357 & 405 & 143 & 618\end{array}$

116 As a result of the parameters' fit, we can deduce the values of $i=0.0354$ and $j=0.0662$, that provide the best reconciliation of actual building prices with the estimated/calculated (subscript- "c") ones developed under formula (10) and presented in the last row of Table 2 (the last row but one lists the estimated values for the rent multiplier).

117 The obtained values for the discount and growth rates can now be used in connection with valuing other buildings (either in fair value or value-in-use $e^{7}$ contexts). However, with reference to the Impairment standard IAS 36 (par.33c), where the respective value-in-use valuations are prepared in conjunction with the impairment testing, one may have to check that the growth rates used do not exceed the long-term average growth rate for the comparables (unless a higher rate can be justified).

\section{$118 \quad$ 7. Remaining service life of the building}

119 For the additional justification of the growth rates accepted for the operating benefits (i) and the underlying land value ( $j$ ) it may be useful to estimate the remaining service life (RSL) of the building, the assessment of which can be developed on the basis of the following considerations.

120 Let's continue considering the market where the properties characterized by two value-affecting parameters $B$ and $L$ - are traded. In this context, the value of each property is some smooth function of its parameters. Therefore, it will be natural to assume that the expected service life for the built property (T) is also some smooth 
function of the parameters: $T=T(L, B)$. Let's attempt to establish the explicit form of this dependency, assuming, as before, that the dependency is a stable one.

121 Consider a subject property with parameters (L,B). For such a property $R S L=T(L, B)$. Over the incremental period $d t$ subsequent to the valuation date the parameters of the property will have sustained a change: the operating benefit $(O B)$ generated by the property will become $(1+i d t) B$, and the land value $(1+j d t) L$. But a property with these characteristics as of the valuation date will have the residual service life of its building equal to ${ }^{T((1+j d t) L,(1+i d t) B)}$. In view of the stability principle, the same service life will attach to the subject property at the end of the period. Having regard to this, the residual service life of our subject building can be determined by summing up the duration of the incremental period and the residual service life of this building at the end of this period:

122

$$
T(L, B)=d t+T((1+j d t) L,(1+i d t) B) .
$$

From this, with an accuracy up to infinitesimals of a higher order, we get:

124

$$
-d t=T((1+j d t) L,(1+i d t) B)-T(L, B)=j L \frac{\partial T}{\partial L} d t+i B \frac{\partial T}{\partial B} d t
$$

But this equality is valid if and only if

126

$$
j L \frac{\partial T}{\partial L}+i B \frac{\partial T}{\partial B}=-1 .
$$

127

We have thus derived a partial differential equation for the unknown function $T$. Moreover, as shown above, the T function goes down to zero at $p=L / B=s$. Having regard to this boundary condition and recalling that $i$

128

$$
T=\frac{1}{j-i} \ln \frac{B s}{L}=\frac{1}{j-i} \ln \frac{s}{p} .
$$

129 Residual service lives estimated under this formula can be considered as useful lives in the context of depreciation accounting. However, if the RSLs calculated according to this formula substantially differ from those appearing credible on the basis of sound technical and economic criteria, this indicates an erroneous choice of the estimates for $i$ and $j$ rates.

$130 \quad$ Table 3 lists residual service life values (in years) estimated according to formula (13) in respect of the four buildings, the parameters for which were included in Table 1. The values in the top line correspond to zero rates for property taxes, while the values in the bottom line reflect a situation with the rates at $m=0.032, q=0.01$.

$131 \quad$ Table 3. Residual services lives obtaining for properties listed in Table 1

$\begin{array}{lllll}\text { Tax rates } & \text { Building } 1 & \text { Building } 2 & \text { Building } 3 & \text { Building } 4 \\ m=q=0 & 54 & 40 & 106 & 42\end{array}$


132 In this example, some questions may arise regarding the seemingly excessive period of service life suggested for Building 3. These durations would have to be crosschecked against the data on the remaining service life of the buildings estimated on the basis of technical criteria (the technical condition of the buildings and their continuing use).

133 Let us now consider a case where $i=j$. Take a building with a PPL less than $s$. Formula (13) would be valid for such a building, given $i j$.

\section{$134 \quad 8$. Building depreciation: its assessment and reflection in financial statements}

135 The findings in Section 5 of this chapter can be used to assess depreciation in buildings. It should be reiterated, however, that "depreciation" in this context is strictly understood to mean the market-based depreciation - a diminution in the fair value of subject property, consonant with the valuation standards.

136 We shall start by noting that up to now all the value-affecting parameters were deemed to be nominal, i.e. incorporating the pace of inflation. However, the foregoing discussion is also valid, when the parameters are recast in real terms, i.e. adjusted for the rate of general inflation in the country. In this instance, the rates $i$ and $j$ shall be treated as the real growth rates for operating benefits and land values (i.e. net of inflation), and the rate $r$ - as a real market discount rate.

137 Let's continue with the discussion of our subject property, which as of the valuation date comprises underlying land with the value $L$ and a building generating income at a rate B. Let's analyze how the fair value of the building changes over an incrementally brief period $d t$. Let's note in the context that the subject property characteristics will have changed by the end of this period. Namely, according to formula (4), the real (i.e. net of inflation) value of the land element will have grown by $(1+j d t)$ times, while the real rate of operating benefits - will have changed by $(1+i d t)$ times. Consequently, the absolute changes in these parameters and for PPL will amount to:

$$
\begin{gathered}
d B=(1+i d t) B-B=i B d t, \quad d L=(1+j d t) L-L=j L d t ; \\
d p=\frac{1+j d t}{1+i d t} p-p=(j-i) p d t .
\end{gathered}
$$

139 Therefore, the real value of the building ${ }^{C=B f(p)}$ will also change. Differentiating this rent multiplier-based building valuation formula we obtain:

140 $d C=f(p) d B+B f^{\prime}(p) d p$.

$141 \quad$ Substituting $d B$ and $d p$ from (14), we derive the amount of change in the real value of the building:

$142 \quad d C=f(p) d B+B f^{\prime}(p) d p=f(p) i B d t+B f^{\prime}(p)(j-i) p d t$.

143 We shall now note that in connection with the physical deterioration of the buildings the annual real incomes from the use of a building tend to decline over time, therefore $i$

$$
-\frac{d C}{d t}=B\left[-p f^{\prime}(p)(j-i)-i f(p)\right] .
$$


Let's correlate this result with the accepted methods of building depreciation accounting in financial statements. Due to obvious reasons, the owners of property can't continuously undertake revaluations of their assets. Therefore, subsequent to the acquisition of property or its last impairment revaluation, the value of property in the international cost model of PP\&E accounting is reflected in financial statements with an allowance for depreciation assessed under one of the applicable methods. Let's find out which of the depreciation methods used in accounting would allow to reflect changes in the fair value of a property asset most closely.

146 For this, let's consider a situation, when using the techniques above we have established, as of the valuation date, the fair value of the building and its residual service life. This fair value is recorded in financial statements as a carrying amount for the subject building. Then, in order to estimate the amount of building depreciation charge in the coming period (over the next year), one has to find first the average depreciation rate over the residual service life of the building, and then apply to this rate a certain Acceleration factor/coefficient (AC). As a measure of this coefficient, 1 (i.e. linear depreciation), or 2 (i.e. the double declining balance method) are often used. Let's clarify, what exact value for the acceleration coefficient should be selected to ensure that the depreciation charges used in accounting reflect as closely as possible the demunition of asset's fair value.

147 We shall begin by noticing that the average rate of depreciation for the building over its remaining service life (T), determined according to formula (13), amounts to:

148 Correlating the depreciation of the building over an incremental period (i.e. formula (16) obtained above) with the average depreciation of the same building over the residual service life (T), we can derive the value of the acceleration coefficient:

149

$$
A C=\left(-\frac{d C}{d t}\right) /\left(\frac{C}{T}\right)=-\frac{i f(p)+p f^{\prime}(p)(j-i)}{(j-i) f(p)} \ln \frac{s}{p}=-\left[\frac{p f^{\prime}(p)}{f(p)}+\frac{i}{j-i}\right] \ln \frac{s}{p}
$$

$150 \quad$ Substituting expression (9) derived for the value of rent multiplier and bearing in mind that $a=(r-i) /(j-i)$, the following obtains subsequent to certain transformations:

151

$$
A C=\left[\alpha \frac{\left(\frac{p}{s}\right)-\left(\frac{p}{s}\right)^{\alpha}}{\alpha-1-\alpha\left(\frac{p}{s}\right)+\left(\frac{p}{s}\right)^{\alpha}}-\frac{i}{j-i}\right] \ln \frac{s}{p} .
$$

152 The following figure 4 charts dependencies $A C(p)$ resulting from certain combinations of $(i, j, r)$.

153 As can be seen, for a typical PPL range the values of acceleration coefficients obtained are close to 2. This implies that the use of double declining balance method for building depreciation would result in a closer reflection of the building fair values by their carrying amounts, than afforded by using any other alternative methods of depreciation accounting. 


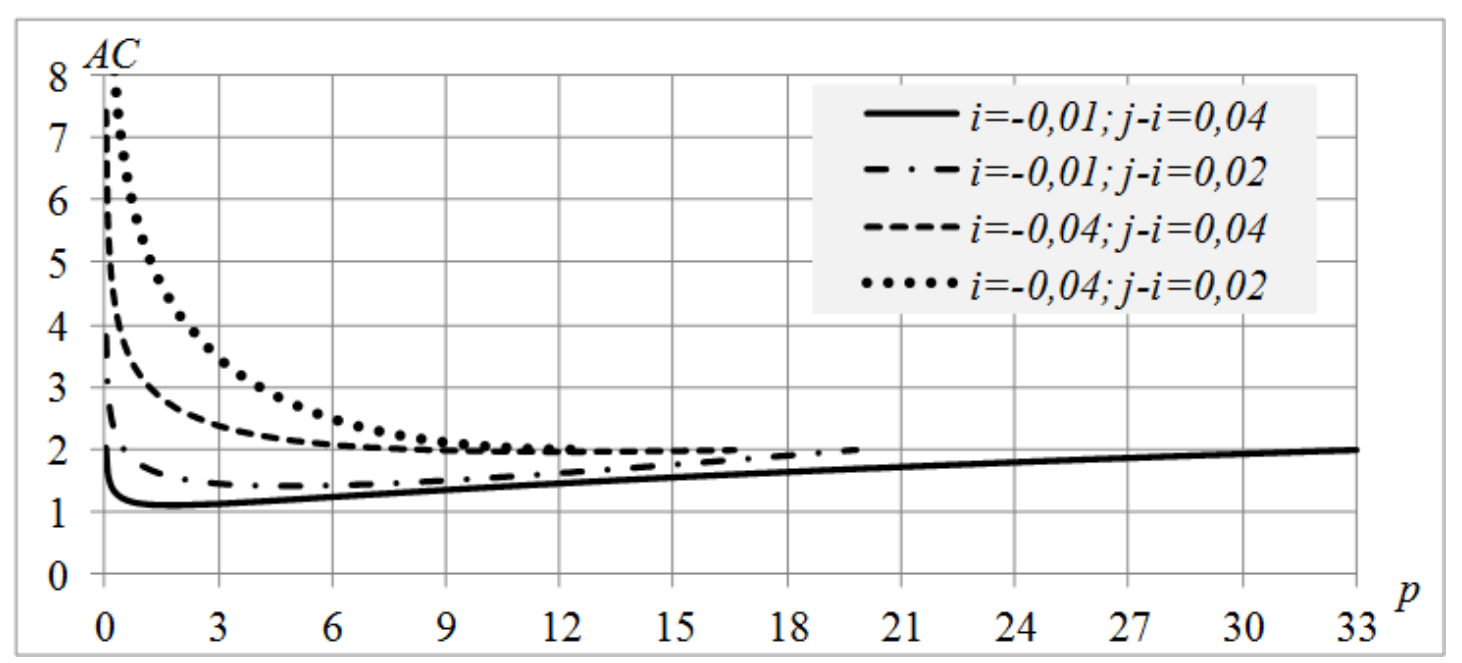

Fig. 4. The functional dependence of the acceleration coefficient on PPL for $r=0,06$ and certain combinations of $i$ and $i-j$.

\section{Conclusions}

156 Empirical evidence shows the fair value of a building may depend on the value of the land on which it is situated. The fact of the matter is that the value of the underlying land sets the conditions for the marginal level of net benefits, which determine whether to continue using the building, or to demolish it or dispose of it on the market at the price of the underlying land value. At the same time, as the building ages the benefits it generates decline relative to the value of the land. Thus, the impact of the land value is in some sense indirect -- it affects the length of the period during which a building can be used efficiently, i.e. the period during which the owner receives net benefits from its use, and as a consequence -- affects the value of the building, i.e. the amount of discounted benefits from the building use over this period.

157 The above considerations formed a basis of the proposed analytical model (in Formula (10)) allowing to develop supportable building element valuations. It is noteworthy that this model uses a formulation of the DCF analysis method. Traditionally this method is geared to using a cash flow forecast for the entire duration of the prospective use of the subject property. A resulting reliance on the abundant Prospective financial information (PFI) reduces the utility of the method from the standpoint of IFRS 13 Fair Value hierarchy for the valuation output. But, in our instance, the DCF method is put to use to delineate a relationship between the values of several comparable properties holding as of the valuation date. This, among other things, allows to mitigate uncertainties associated with the long-term forecasting of income and determination of terminal values, as well as to account for the rates of inflation and property taxation rates prevalent as of the valuation date.

158 The model can be used not only for the purposes of estimating the values of buildings on the basis of income arising from their use, but also for solving inverse problems -- assessing market rents for buildings, the value of which is a known item of data. To solve all these issues with respect to the building element, it relies on a limited number of well-defined inputs: the current level of overall property income (B) and of the value of land $(L)$, a discount rate ( $r)$, plus currently prevalent inferred rates of the value changes $(i, j)$ and existing property taxation rates for land and buildings $(q, m)$. The 
parsimoniousness of information required to operate the model, as well as its grounding in the market data from the present time (as opposed to the conventional use of Prospective financial information for DCF analysis) are some of the features of the model with a positive effect in terms of IFRS 13 Fair Value hierarchy classification principles.

159 Additionally, we have shown that the described model can be used to choose such building depreciation mechanisms/patterns that would enable to reflect economic building depreciation processes in the financial statements in a more adequate way.

\section{Acknowledgements}

161 The author gratefully acknowledges the editorial assistance that he received from Andrey Artemenkov, MRICS.

162 List of acronyms used throughout the chapter:

DCF-Discounted cash flow analysis;

IFRS - International Financial Reporting Standards;

$H A B U-H i g h e s t$ and best use;

$O B$-Operating benefits;

PFI-Prospective financial information;

$P P L$ - Payback period for Land;

RM-Rent multiplier;

Примечания:

1. The selection by assessors of a projection period of certain, usually shorter, duration is informed by the need to reflect material changes in the market situation towards the end of such period. But such changes would exert their principal pull on the reversionary value of the building.

2. Adjustments for underutilization of rental space and under-collection of rents should also be considered even when all the space in the building is fully occupied year around and no rents under-collected over the past year. This would help account for the risk of respective losses going forward.

3. In mathematical analysis, a function which is continuous and differentiable at every point is called smooth. The dependences between economic indicators are usually such.

4. These assumptions, inter alia, suggest a more precise specification for the range of "similar buildings" traded on the property market in question. Consonant with such assumptions, similar buildings are regarded to be those buildings which are characterized by one and the same most rational use and are identical in terms of land value growth rates, as well as OBs growth rates.

5. The equalities presented here and below should be regarded as accurate with the accuracy up to the infinitesimals of a higher order compared to the length of the $d t$ time period. This will be reiterated on occasion.

6. Generally all DCF applications assume some use of the subject property, but such uses can be market-consistent (resulting in the derivation of market/fair value), or entity-specific (resulting in the derivation of value-in-use). International Accounting Standard IAS 36 on Impairment imposes some additional requirements on the standard-consistent notion of value-in-use, such as the use of pre-tax discount rates (our model is consistent on the use of such a rate--therefore, nothing precludes its application in the value-in-use derivation contexts).

7. In case value-in-use is sought, the use of comparables selected should be consistent with a specific use to which the subject property is put by the reporting entity; in fair value contexts, on the other hand, the use of comparables should reflect the highest and best use (HABU) of subject property, defined consistent with the HABU requirements in the International Standard IFRS 13.

8. The rates $i$ and $j$ are considered to be a feature of the market, and not that of specific traded properties. It means that each traded property would be characterized by a"general" operating benefits growth rate $i$, and the land value growth ratej. 


\section{Библиография:}

1. Baum A. et al, The Income approach to property valuation, 6 ed, Routledge, 2011

2. Sayce S., Smith J., Cooper R., Venmore-Roland P. et al, Real Estate Appraisal: From Value to Worth. Blackwell Publishing Ltd., 2006.

3. Leyfer L.A., YDirect capitalization method. Generalized Inwood Model $\Phi / /$ in Voprosi Otsenki, 63 , 2006, pp. 15-20 http://www.labrate.ru/leifer/lev leifer articlemodel inwood.htm (in Russian)

4. Strokov A.V., Strokova D.V. YCapitalization Rate and the Return on Investments. Part1 // http://www.appraiser.ru/default.aspx?SectionID=35\&Id=2969, Part. 2 // http://www.appraiser.ru/default.aspx?SectionId $=35 \& I d=2972$. (in Russian)

5. Gribovsky S.V., Ivanova E.N., Lvov D.S., Medvedeva O.E. (2003) Real Estate Valuation, Interreklama Publishers, 2003 (In Russian)

6. Appraisal Institute, The Appraisal or real estate, 14th ed., Appraisal Institute, 2013

7. IVSC, The International Valuation Standards 2017. The International Valuation standards Council. London 2017 (www.ivsc.org)

8. IVSC, The International Valuation Standards 2007, The International Valuation standards Committee. London 2007.

9. Majewska B., Why regression analysis is not best valuation practice. TEGoVA European Valuer, July 2017, Issue No 8. Pp. 34.

10. Smolyak S.A. Problems and Paradoxes in the Valuation of Machinery and Equipment, RIO MAOC, Moscow, 2008. (in Russian)

11. Smolyak S.A., CModels for Estimating Depreciation in Plants, Machinery, and Equipment: Analysis and Proposals $\Phi / /$ Journal of Property Tax Assessment \& Administration, Volume 9, Issue 3, 2012. pp. 47-86.

12. Kamke E. Differentialgleichungen, L? sungsmetoden und L? sungen, Band II, Partielle Differentialgleichungen erster Ordnung f?r eine gesuchte Funktion. Academische Verlagsgesellschaft, Leipzig, 1948. (in German) 


\title{
Assessment of fair values and depreciation in buildings: new applications for the Discounted Cash Flow analysis
}

\author{
Sergey Smolyak
}

CEMI RAS

107564 MOSCOW Russia, Krasnobogatyrskaya ul., d.27, kv. 129

\section{Abstract}

The findings from this chapter are applicable to such Real Property accounting situations in which the value of land is assumed to be known, but the value of building erected on it (and, by implication, the value of overall property) needs be determined on the basis of known income arising from the overall property. As is well known, across most accounting regimes globally building is usually a depreciable element in the costbased accounting model, while a fee-simple land element in the property is deemed perpetual and not subject to depreciation-necessitating a separate accounting treatment for both elements in the overall property. Given this context, this chapter provides analytical framework and guidance to help accountants to do the following: 1) To determine the value of the building element for the initial recognition in the accounts of entities, without recourse to a meticulous buttom-up cost analysis (or unit costs) of substitution. 2) To justify the economically rational residual service life of the building element. 3) To establish the economically rational depreciation pattern for the building element. To achieve these objectives, this chapter uses a mathematical model formulated in continuous time and based on the well-known DCF analysis discounting principles, however, because the model is framed in continuous time its advantage is in that it allows for less burdensome forecast inputs (i.e. prospective financial information) than the conventional DCF format in discrete time. It uses the explicit assumptions for the rates of change as inputs, instead.

Keywords: real property, building value, assessment, depreciation, DCF analysis, $H A B U$ principle, mathematical model, remaining service life.

Date of publication: 03.02.2019

\section{Citation link:}

Smolyak S. Assessment of fair values and depreciation in buildings: new applications for the Discounted Cash Flow analysis // Herald of CEMI. - 2018. - V. 1. - Issue 4. URL: https://cemi.jes.su/s265838870000159-7-1/. DOI: 10.33276/S0000159-7-1 